\title{
A comparative study between closed vs open reduction of type 3 supracondylar fracture of humerus fixed with $K$ wire in children
}

\author{
Aminul Islam Mamood* \\ Department of Orthopaedic, Calcutta National Medical College, Kolkata, West Bengal, India \\ Received: 26 December 2021 \\ Revised: 09 February 2022 \\ Accepted: 10 February 2022

\section{*Correspondence:} \\ Dr. Aminul Islam Mamood, \\ E-mail: aminulislammamood@gmail.com \\ Copyright: () the author(s), publisher and licensee Medip Academy. This is an open-access article distributed under \\ the terms of the Creative Commons Attribution Non-Commercial License, which permits unrestricted non-commercial \\ use, distribution, and reproduction in any medium, provided the original work is properly cited.
}

\begin{abstract}
Background: Supracondylar fracture of humerus is one of the most common fractures in upper limbs in children's, more common in male child and peak age between 5 to 10 years. Object of this study was to compare the outcome between open vs closed reduction with $\mathrm{K}$ wire fixation for supracondylar fracture of humerus.

Methods: Children with type 3 supracondylar fracture of humerus were categorized in to group A (closed) and group B (open). All children were followed for 6 months and outcome of treatment was evaluated using Flynn's criteria.

Results: The study consisted of 35 types 3 supracondylar fractures. Group A (closed reduction) had 20 cases, among them were 15 males and 5 females. Group B (open reduction) had 15 cases, among them were 12 males and 3 females. Peak age between 5-10 years and male preponderance in both groups.

Conclusions: Closed reduction and $\mathrm{K}$ wire fixation had very good results for type 3 supracondylar fractures of humerus in children than open reduction. In cases where proper/satisfactory closed reduction not achieved open method used.
\end{abstract}

Keywords: Type 3 supracondylar fractures, Humerus, $\mathrm{K}$ wire, Closed reduction, Open reduction

\section{INTRODUCTION}

In the upper limb fractures the supracondylar fracture of the humerus in children is the most common. It constitutes about $55 \%$ to $75 \%$ of fractures around the elbow in children. ${ }^{1}$ Peak age around 5-10 years and male preponderance. $^{2}$ It is highly complicated fractures if not treated properly may develops malunion, stiff elbow, neurovascular deficits.

Type 1 supracondylar fracture treated only above elbow pop (plaster of Paris) slab application and immobilized in 90-degree flexion.

Type 2 are treated conservatively with closed reduction and above elbow pop cast application in the 90-degree flexion.
Type 3 displaced fractures are treated with various methods, they are following: Closed reduction and pop cast, closed reduction with skeletal traction, closed reduction and percutaneous $\mathrm{K}$ wiring and open reduction and $\mathrm{K}$ wire fixation. ${ }^{3}$

Closed reduction and pop cast has various challenges like difficulty in reduction and maintenance of reduction after manipulation. Patients had malunion, Volkmann's ischemic contracture, cubitus varus deformity and elbow stiffness during the follow up of these methods of treatment. ${ }^{4,5}$

So, closed reduction and $\mathrm{K}$ wire and open reduction and $\mathrm{K}$-wire are more useful methods for stable fixation.

Open methods have its principal advantages like better anatomical fixation and functional outcome. ${ }^{6}$ 


\section{Objectives}

Our study is to compare the outcome of both closed and open method for the treatment of type 3 supracondylar fracture, using Flynns criteria (Table 1) for the patients follow up.

Table 1: Flynn's criteria for assessing the range of motion and loss of carrying angle. ${ }^{3}$

\begin{tabular}{|lll|} 
Variables & $\begin{array}{l}\text { Cosmetic } \\
\text { factor, } \\
\text { carrying-angle } \\
\text { loss (degree) }\end{array}$ & $\begin{array}{l}\text { Functional } \\
\text { factor, } \\
\text { movement-loss } \\
\text { (degree) }\end{array}$ \\
\hline Excellent & 0 to 5 & 0 to 5 \\
\hline Good & 5 to 10 & 5 to 10 \\
\hline Fair & 10 to 15 & 10 to 15 \\
\hline Poor & $>15$ & $>15$ \\
\hline
\end{tabular}

\section{METHODS}

It is a comparative study conducted among the patients admitted in Calcutta national medical college and hospital with supracondylar fracture of humerus considering the inclusion and exclusion criteria. The study period was for 1 year from September 2019 to august 2020. The institutional ethical committee clearance was taken before the start of the study.

\section{Inclusion criteria}

Children's who had age between 3-13 years, closed fractures, recent onset up to 7 days, type 3 fractures and simple fractures were included in the study.

\section{Exclusion criteria}

Children's who had age less than 3 and more than 13, open fractures, older onset more than 7 days, type 1 and 2 fractures and complicated fractures associated with vascular, neurological injuries were excluded from the study.

All children attending our OPD and emergency with history of fall on outstretched hand, pain, swelling, unable flexion and extension, ecchymosis, deformity, evidence of compartment syndrome. Vascular and neurological status of the limb. X-ray AP and LAT view of elbow were taken to conform fracture.

Supra condylar fracture was classified under Gartland's classification (Table 2). Type I undisplaced treated conservatively with above elbow pop slab with 90-degree flexion and extension. Type II displaced with posterior cortex intact treated with closed reduction and above elbow pop slab.

Type III displaced fracture included in this study group A treated with closed reduction and percutaneous $\mathrm{K}$ wire fixation, group $\mathrm{B}$ with open reduction and $\mathrm{K}$ wire fixation.
Table 2: Gartland's classification. ${ }^{7}$

\begin{tabular}{|ll|}
\hline Types & Classifications \\
\hline Type I & Undisplaced \\
\hline Type II & Displaced (Intact posterior cortex) \\
\hline Type III & $\begin{array}{l}\text { Displaced (Postero medial and } \\
\text { postero lateral) }\end{array}$ \\
\hline
\end{tabular}

Post operative $\mathrm{X}$ ray were taken on same day and 1 week later to determine the maintenance of reduction. After 3 weeks slab was removed and active range of motion exercises were encouraged. $\mathrm{K}$ wires were removed after 4 to 6 weeks. explain patient and attendance for massage and passive stretching of elbow joint.

Regular follow up was done every month for period of 6 months. examine the patients clinically and radiologically, range of motion and carrying angle using Flynns criteria (Table 1).

The results were compared between groups and analysed. Chi-square test was used for comparing the outcome between conservative and surgical treatment using SPSS software and $\mathrm{p}<0.05$ was considered as significant.

\section{RESULTS}

Thirty-five cases taken for this study have been categorized according to age, sex. Group A (closed reduction) had 20 cases among them were 15 males and 5 females. Group B (open reduction) had 15 cases among them were 12 males and 3 females. The patients were between the age of 3 to 13 years. In group A, 17 children were in the age of 3 to 9 years and group B had 10. In group A 3 children were in age of 10 to 13 and group B had 5 .

Table 3: Case distribution among each group.

\begin{tabular}{|ll|}
\hline Groups & Number of cases \\
\hline Group A (closed reduction) & 20 \\
\hline Group B (open reduction) & 15 \\
\hline
\end{tabular}

Table 4: Sex distribution in each group.

\begin{tabular}{|lll|}
\hline Groups & Male & Female \\
\hline Group A & 15 & 5 \\
\hline Group B & 12 & 3 \\
\hline
\end{tabular}

Table 5: Age distribution of each group.

\begin{tabular}{|lll|}
\hline Groups & 3-9 years & 9-13 years \\
\hline Group A & 17 & 3 \\
\hline Group B & 10 & 5 \\
\hline
\end{tabular}

The 20 cases were operated with closed reduction and $\mathrm{K}$ wiring under $\mathrm{c}$ arm guidance. The 15 cases were operated with open reduction with triceps splitting approach.

In group A of 20 cases two had pin site infection which healed after $\mathrm{K}$ wire removal. One case had elbow stiffness 
which improved with physiotherapy. In group B of 15 cases three had elbow stiffness which improved with physiotherapy, one had superficial infection.

Union rates were 4 weeks in both groups.

Table 6: Complications of each group.

\begin{tabular}{|ll|l|}
\hline Complications & $\begin{array}{l}\text { Group A, } \\
\text { (closed) }(\%)\end{array}$ & $\begin{array}{l}\text { Group B, } \\
(\text { open) }(\%)\end{array}$ \\
\hline Pin site infection & $2(10)$ & $0(0)$ \\
\hline Elbow stiffness & $1(5)$ & $3(20)$ \\
$\begin{array}{l}\text { Superficial } \\
\text { infection }\end{array}$ & $0(0)$ & $1(6.67)$ \\
\hline
\end{tabular}

In group A, 19 cases (95\%) had excellent and $1(5 \%)$ had good results. In group B $12(80 \%)$ excellent results, 2 $(13.3 \%)$ good and $1(6.67 \%)$ fair result.

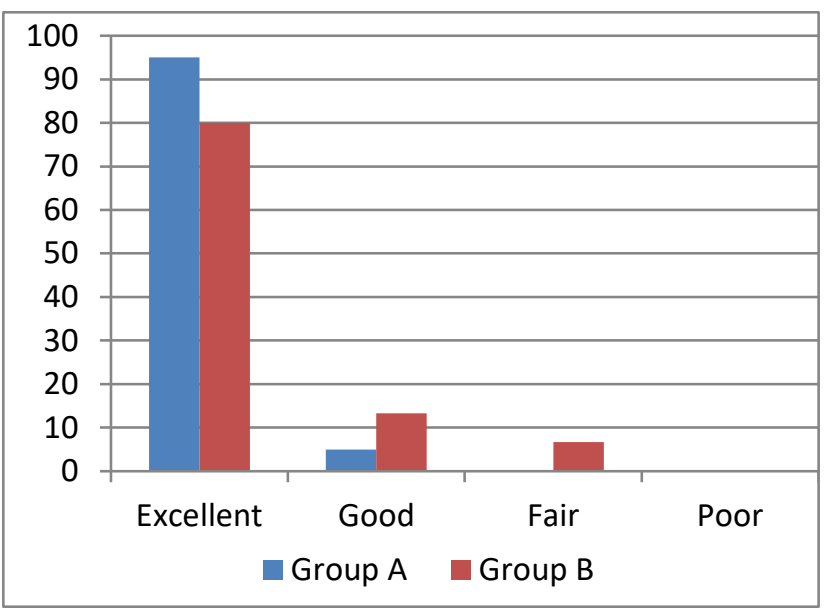

Figure 1: Study results according to Flynn's criteria.

\section{DISCUSSION}

The average annual incidence of elbow fractures in childhood was 12 per 10,000 . Supracondylar humerus fracture is the most common elbow fracture in children. It constitutes about $55 \%$ of all the elbow fractures. ${ }^{8}$ As the skeleton is immature in children, the fractures occur commonly in the first decade of life. The incidence of supracondylar fractures has two peaks, one between 4-5 and other in 5-8 years of age. In this study, majority $70 \%$ of children were in the age group of 3-9 years. In this present study, the mean age of presentation was 7 years. In group A minimum age was 3 years and maximum age was 12.6 years. In group B minimum age was 3.6 years and maximum age was 13 years. According to Ramsey et al the mean age of presentation was 7 years. ${ }^{9}$ According to a study done by Andrew et al, the average age of presentation was 6.7 year. ${ }^{5}$ There was male predominance in this study. In a study done by Mazda et al male predominance was seen just like our study. ${ }^{9}$ In the present study, majority $75 \%$ sustained fractures due to sports related injury. Fransworth et al in their study $70 \%$ of cases sustained fracture due to fall. ${ }^{11}$ Left sided fracture was seen in $80 \%$ of children in this study as majority of the children have right sided dominance. All the cases reported in our study was extension type of supracondylar fractures, no cases of flexion type reported. According to the literature extension type constitute $97-98 \%$ and flexion type constitute only $2-3 \% .^{12}$

In this study, majority $(60 \%)$ of children were operated within 24 hours of injury. According to a study by Ramsey et al all $100 \%$ cases were operated on the same day of admission. ${ }^{9}$ According to David Skaggs, the average interval of time of injury and operation was 1.4 days in their study. ${ }^{1}$ There was statistically significant association between rate of complication and timing of surgery $(\mathrm{p}=0.02)$. There was no association between outcome of surgical treatment and timing of surgery.

In a study done by Pham et al $75.8 \%$ of children with Gartland type IIB and III supracondylar fractures were treated conservatively with Blount's method. The authors had satisfactory outcome of $90 \%$ according to Flynn's criteria and only $2 \%$ of cubitus varus deformity in their study. So according to Pham, Blount's method shows reasonable results and can be followed for type III fractures. ${ }^{13}$ One more study by Muccioli et al also had satisfactory results with Blount's technique. ${ }^{14}$ In the present study, $57.14 \%$ were treated by closed reduction and percutaneous $\mathrm{K}$ wire fixation. In a comparative study done at Serbia, $37(39.78 \%)$ children who were treated with closed reduction and percutaneous pinning $100 \%$ had satisfactory outcome according to Flynn's criteria (Table 1). ${ }^{15}$ In the present study, $42.85 \%$ of cases were operated by open reduction and percutaneous $\mathrm{K}$ wire fixation.

In the study done by Weiland et al all the 52 displaced supracondylar fractures were treated surgically by open reduction and $\mathrm{K}$ wire fixation. ${ }^{5} \mathrm{In}$ a Chinese retrospective study, all 83 patients who were treated by open reduction and $\mathrm{K}$-wire fixation had $90.4 \%$ excellent results in the treatment outcome evaluated by Flynn criteria (Table 1). ${ }^{16}$ In a study done by Gowda et al all 50 patients who were treated by open reduction and internal fixation with $\mathrm{K}$-wire had reported $10 \%$ of ulnar nerve palsy and $83.3 \%$ had excellent/good outcome. ${ }^{17}$ In a study done by Mazda et al $92 \%$ of children who had undergone open reduction with internal fixation had excellent outcome according to Flynn criteria. $^{10}$

In this study, 20 cases were operated with closed reduction and $\mathrm{K}$ wiring under $\mathrm{C}$ arm guidance. The 15 cases were operated with open reduction with triceps splitting approach followed by pinning. In group A of 20 cases two had pin site infection which healed after $\mathrm{K}$ wire removal. One case had elbow stiffness which improved with physiotherapy. In group B of 15 cases three had elbow stiffness which improved with physiotherapy, one had superficial infection.

The average time of fracture union was 4 weeks in both the groups. In our study patient was followed up every week, 
post operative $\mathrm{x}$ ray were taken after 4 weeks. Fractures showed good union by 4 weeks and $\mathrm{k}$-wires were removed. Later children were instructed with active movements of elbow joints. if good range of motion not achieved then advised physiotherapy and reviewed regularly. In group B open reduction cases stitched removal done on 10 to $14^{\text {th }}$ post op day.

In our study $19(95 \%)$ cases had excellent results and one (5\%) had good results, in group A, in group B, 12 (80\%) cases had excellent results and two (13.33\%) good and one (6.67\%) fair result. (Study results according to Flynn's criteria). There was highly excellent / good outcome with closed reduction compared to open.

In our study two cases of pin tract infection and one elbow stiffness in group A and three cases of elbow stiffness and one superficial infection in group B post operative complication observed. Which were managed by antiseptic dressing, antibiotic therapy and physiotherapy of elbow.

\section{CONCLUSION}

Supracondylar fracture of humerus should be operated as early as possible to reduce the rate of complications. The present study shows closed reduction and $\mathrm{K}$ wiring is a better modality for type 3 supracondylar fracture of humerus in children, it avoids stiffness of elbow, delayed soft tissue healing as compared to open methods. In cases where proper/satisfactory closed reduction not achieved open method is preferred.

\section{Funding: No funding sources}

Conflict of interest: None declared

Ethical approval: The study was approved by the institutional ethics committee

\section{REFERENCES}

1. Omid R, Choi PD, Skaggs DL. Supracondylar humeral fractures in children. J Bone Joint Surg. 2008;90:1121-32.

2. Cheng JCY, Lam TP, Maffulli N. Epidemiological features of supracondylar fractures of the humerus in Chinese children. J Pediatr Orthop Part B. 2001;10(1):63-7.

3. Picado VA, Moran G, Moraleda L. Management of supracondylar fractures of humerus in children. Bri Editorial Society Bone Joint Surg. 2018;3:526-40.

4. Sibinski M, Sharma H, Bennet GC. Early versus delayed treatment of extension type -3 supracondylar fractures of humerus in children. J Bone Joint Surg [Br]. 2006;88:380-1.

5. Weiland AJ, Meyer S, Tolo VT, Berg HL, Mueller J. Surgical treatment of displaced supracondylar fractures of the humerus in children. Analysis of fifty- two cases followed for five to fifteen years. J Bone J Surg. 1978;60(5):657-61.

6. Chateau FPW, McIntyre ML. An Analysis of open Reduction of Irreducible Supracondylar Fractures of the Humerus in children. Can J Surg. 1998;41(2):1128.

7. Gartland JJ. Management of Supracondylar Fractures of the Humerus in Children. Surg Gynecol Obs. 1959;109(2):145-54.

8. Landin LA, Danielsson LG. Elbow fractures in children: An epidemiological analysis of 589 cases. Acta Orthop. 1986;57(4):309-12.

9. Ramsey RHGJ. Immediate open reduction and internal fixation of severely displaced supracondylar fractures of the humerus in children. Clin Orthop Relat Res. 1973;90:131-2.

10. Mazda K, Boggione C, Fitoussi F, Penneçot GF. Systematic pinning of displaced extension-type supracondylar fractures of the humerus in children. $\mathbf{J}$ Bone J Surg. 2001;83(6):888-93.

11. Farnsworth CL, Silva PD, Mubarak SJ. Etiology of supracondylar humerus fractures. J Pediatr Orthop. 1998;18(1):38-42.

12. Delniotis I, Dionellis P, Gekas CC, Arapoglou D, Tsantekidis D, Goulios V et al. Flexion-type supracondylar humeral fracture with ulnar nerve injury in children: two case reports and review of the literature. Am J Case Rep. 2020;21:e921293-1-6.

13. Pham TT, Accadbled F, Abid A, Ibnoulkhatib A, Iniguez BX, Wargny $\mathrm{M}$ et al. Gartland types IIB and III supracondylar fractures of the humerus in children: is Blount's method effective and safe. J Shoulder Elb Surg. 2017;26(12):2226-31.

14. Muccioli C, Batti ES, Oborocianu I, Rosello O, Solla F, Chau E et al. Outcomes of Gartland type III supracondylar fractures treated using Blount's method. Orthop Traumatol Surg Res. 2017;103(7):1121-5.

15. Ducic S, Bumbasirevic M, Radlovic V, Nikic P, Bukumiric Z, Brdar R et al. Displaced supracondylar humeral fractures in children: Comparison of three treatment approaches. Srp Arh Celok Lek. 2016;144(1-2):46-51.

16. Li M, Xu J, Hu T, Zhang M, Li F. Surgical management of Gartland type III supracondylar humerus fractures in older children: A retrospective study. J Pediatr Orthop Part B. 2019;28(6):530-5.

17. Gowda PM, Mohammed N. A Study of Supracondylar Fractures of Humerus in Children by Open Reduction and Internal Fixation with Kirschner Wires. Indian J Clin Pract. 2014;25(6).

Cite this article as: Mamood AI. A comparative study between closed vs open reduction of type 3 supracondylar fracture of humerus fixed with $\mathrm{K}$ wire in children. Int J Res Orthop 2022;8:188-91. 